\title{
Editorial
}

\section{A difficult beginning}

Anuradhapura clinical society (ACS) took a momentous decision this year to improve the quality of Anuradhapura Medical Journal (AMJ), the official journal of ACS. Moving away from the tradition of appointing an editor annually with the change of office bearers of ACS, the society appointed two of us as editors for unlimited period to elevate the quality of AMJ. Previously AMJ was a part of annual scientific sessions and from this year, it was decided to go for a proper journal rather than a conference publication. For all practical reasons we are on probation now!

AMJ has been in existence for six volumes. We can assume minimum of six published issues if at least one issue per volume was published, and that's lot of work. One of the first things we have done is to obtain an International Standard serial Number (ISSN) and digitalize the journal. With the help of Sioux Cumming and INASP we have managed to have the volume five and six in the Sri Lanka Journals Online (SLJOL) (1). This issue (volume seven) is the first issue under our stewardship. In this issue, we have two original articles, two case reports about bugs' bites, two perspectives, and a review on rhinosporidiosis by a world-renowned expert. Volume seven will have one issue. Hopefully volume eight will at least have two issues per year, Yala and Maha.

All original articles, case reports, and perspectives published in this issue are peer-reviewed but not refereed, showing the red card is our job although we are heavily influenced by the reviewers. If we acquire enough merit in this birth, we will be bestowed with reviewers who are conscious of deadlines. But, you researchers can't wait till the next birth so please keep sending your research to us. If you have not heard from us still, it is because your manuscripts are being peer reviewed.

There is a Sinhalese adage that "a devils abode is constructed according to the devil". The quality of the journal is reflected on the articles it receives. But the manuscripts are submitted according to the quality of the journal (impact factor, indexation, circulation,). This is a vicious circle almost similar to what we and many others faced as start up researchers yesteryear. Without a grant, it is difficult to do research but to receive a grant you have to show research (publications). Journal impact factors should not be used to assess individual researcher's contribution to science and for hiring, promotion, or funding decisions (2). Impact factors can be manipulated by journal editors and Thomson Scientific (the private company who creates impact factors) is neither transparent about the process or have a clear policy (3).

We are determined to elevate the quality of the journal. You will be the jury, but don't be a silent assassin. Please let us know what you think at least by an E-mail. Otherwise, same fate that happened to our ancient kingdom of Rajarata will befall on the AMJ!

Sisira Siribaddana nipuna@stmail.1k

Suneth Agampodi sunethagampodi@yahoo.com

\section{References}

1. Anuradhapura Medical Journal 2012 [cited 24 September 2013]. Available from:http://www.sljol.info/index.php/AMJ/index/

2. San Francisco Declaration on Research Assessment 2012 [cited 24 September 2013]. Available from:http://am.ascb.org/dora/files/SFDeclarationFINAL.pdf

3. The impact factor game: It is time to find a better way to assess the scientific literature. PLoS medicine 2006; 3: 291-92. 